\title{
O TRABALHO DOS PROFESSORES ORIENTADORES DE ESTÁGIO EM CURSOS DE FORMAÇÃO DE PROFESSORES
}

\author{
EL TRABAJO DE LOS PROFESORES DE PRÁCTICAS DOCENTES EN \\ CARRERAS DE FORMACIÓN DE PROFESORES
}

\author{
WORK TEACHERS GUIDING OF TRAINING IN COURSES OF TEACHER \\ EDUCATION
}

\section{Nadiane FELDKERCHER ${ }^{1}$}

RESUMO: O estágio curricular na formação de professores objetiva aproximar o estagiário da escola básica, seu futuro campo de atuação. É uma atividade supervisionada por implicar o acompanhamento e orientação do professor orientador de estágio (vinculado à universidade) e do professor regente da turma (vinculado à escola básica). Nesse estudo objetivamos conhecer e analisar o trabalho desenvolvido pelos professores universitários que orientam o estágio de um curso de formação de professores de matemática de uma universidade pública do sul do Brasil. Utilizamos a entrevista como instrumento de coleta de dados junto a dois professores orientadores de estágio. As análises estiveram pautadas em orientações legais sobre o estágio e em autores como Pimenta e Lima (2004), Pimenta (2006), Zabalza (2004) e Zeichner (2009). Dentre os resultados, apontamos que a demanda de trabalho dos orientadores é ampla e, muitas vezes, esses professores não possuem as condições mínimas para acompanhar e supervisionar os estagiários. O descompasso entre o calendário escolar e o calendário universitário foi uma limitação identificada no desenvolvimento do estágio nesse curso. Percebemos a necessidade de uma maior aproximação entre universidade e escola e a revisão do que se refere ao trabalho cooperativo entre os dois professores orientadores de estágio desse curso.

PALAVRAS-CHAVE: Professor universitário. Estágio curricular supervisionado. Orientação de estágio.

RESUMEN: La pasantía (o práctica curricular) en la formación de profesores objetiva aproximar el pasante a la escuela básica, su futuro espacio de actuación. Es una actividad supervisada por implicar el acompañamiento y orientación del profesor responsable por las prácticas supervisadas (vinculado a la universidad) y del profesor responsable por el grupo de alumnos de la escuela (vinculado a la escuela básica). En ese estudio tenemos como objetivo conocer y analizar el trabajo desarrollado por los profesores universitarios que dirigen la práctica de una carrera de formación de profesores de matemáticas de una universidad pública del sur de Brasil. Utilizamos la entrevista como instrumento de recopilación de datos a dos profesores supervisores de

\footnotetext{
${ }^{1}$ Doutora em Educação pelo Programa de Pós-Graduação em Educação da Universidade Federal de Pelotas. Participou do Programa de Doutorado Sanduíche (PDSE-CAPES), na Universidade de SevillaEspanha, sob orientação da professora Cristina Mayor Ruiz. Bolsista CAPES/Demanda Social durante o doutorado. Foi bolsista pós-doc FAPERGS/CAPES na área de Educação, junto ao Programa de PósGraduação em Educação da Universidade Federal de Pelotas, sob orientação do professor Álvaro Moreira Hypolito. Email: nadianef@gmail.com
} 
la Pasantía. Los análisis estuvieron basados en orientaciones legales sobre la Pasantía y en autores como Pimenta y Lima (2004), Pimenta (2006), Zabalza (2004) y Zeichner (2009). De los resultados, verificamos que la demanda de trabajo de los profesores de prácticas docentes es amplia y, muchas veces, esos profesores no poseen las condiciones mínimas para dirigir y orientar a los pasantes. El descompás entre el calendario de la escuela y el calendario de la universidad fue una limitación identificada en el desarrollo del pasante en esa carrera. Nos dimos cuenta de la necesidad de mayor aproximación entre universidad y escuela y la revisión de lo que se refiere al trabajo cooperativo entre los dos profesores que orientaban la pasantía de esa carrera.

PALABRAS CLAVE: Profesor universitario. Pasantía. Orientación de pasantía.

ABSTRACT: The stage curriculum in teacher education aims to bring the trainee primary school, their future field. It is activities supervised by entail monitoring and guidance of the teacher training adviser (linked to the university) and the classroom teacher's class (linked to the basic school). In this study we aimed to identify and analyze the work done by academics to guide the stage of a training course for teachers of mathematics at a public university in southern Brazil. We use the interview as an instrument of data collection along with two faculty advisers' internship. Analyzes were guided by legal guidelines on the stage and authors such as Pimenta and Lima (2004), Pimenta (2006), Zabalza (2004) and Zeichner (2009). Among the results, we point out that the demand for labor of guiding is broad and often, these teachers do not have the minimum requirements to monitor and supervise the interns. The mismatch between the school calendar and timetable university was a limitation identified in the development stage of this course. We realized the need for a closer relationship between school and university and review of what refers to cooperative work between the two faculty advisers internship this course.

KEYWORDS: University teacher. Curricular supervised training. Orientation training.

\section{O estágio na formação de professores: alguns apontamentos}

Nesse artigo abordamos o trabalho desenvolvido pelos professores universitários que assumem a função de orientar o estágio curricular supervisionado em cursos de formação de professores. Para tal levamos em consideração orientações legais e discussões teóricas sobre o estágio na formação de professores. Objetivamos, mais especificamente, conhecer e analisar o trabalho desenvolvido pelos orientadores de estágio de um curso de formação de professores de matemática da Universidade Federal de Pelotas (UFPel), situada no sul do Brasil, segundo a perspectiva dos próprios professores $^{2}$.

\footnotetext{
${ }^{2}$ Este artigo é um recorte das análises desenvolvidas na pesquisa intitulada "O estágio na formação de professores presencial e a distância: a experiência do curso de matemática da UFPel” desenvolvida a nível de mestrado em Educação.
} 
Percebemos o estágio curricular supervisionado na formação de professores como um conjunto de atividades pedagógicas que o estagiário/professor em formação desenvolve para experimentar e vivenciar sua futura profissão. Normalmente a maior parte das atividades do estágio é desenvolvida na escola de educação básica. Sendo o estágio uma atividade de experimentação, de vivências, de aprendizagens da profissão ela requer uma orientação ou acompanhamento de profissionais reconhecidos ou com experiência na área, que são tanto o professor universitário (orientadores) quanto o professor da escola básica (professor regente de turma). Em outras palavras Pimenta (2006) define que o estágio é composto por "atividades que os alunos deverão realizar durante o seu curso de formação, junto ao campo futuro de trabalho" (p. 21) e que é um "processo de apreensão da realidade concreta, que se dá através de observação e experiências" (p. 76). A autora complementa ainda que o estágio "é uma atividade teórica (de conhecimento e de estabelecimento de finalidades) na formação do professor. Instrumentalizadora da práxis (atividade teórica e prática) educacional. De transformação da realidade existente.” (2006, p. 121-122).

Estagiar é muito mais do que dar aulas: é se inserir no espaço escolar, conhecer essa realidade, identificar seus problemas, buscar soluções pertinentes, participar da gestão da escola, ensinar, instigar a aprendizagem de todos os alunos, dentre outros. $\mathrm{O}$ aluno estagiário recebe formação para tornar-se professor por parte da universidade e também por parte da escola. Assim sendo, o estágio também é uma forma de aproximação entre universidade e escola. Tanto uma quanto a outra instituição pode proporcionar ao estagiário a formação teórica e a formação prática e esses alunos podem transitar da universidade para a escola e vice-versa levando e trazendo conhecimentos, aprendendo e ensinando. Porém, muitas vezes não há espaços institucionalmente organizados para que a aproximação entre universidade e escola ocorra de maneira mais formal, o que faz com que as duas instituições fiquem isoladas. Muitas vezes se pensam mas não se desenvolvem estratégias para essa efetiva aproximação, para a promoção do diálogo entre essas duas instituições formativas, para as aprendizagens e reflexões coletivas sobre o ser professor.

No contexto do desenvolvimento do estágio e de uma possível aproximação mais efetiva entre universidade e escola, Pimenta e Lima (2004) apontam que em "seminários conjuntos com os professores das escolas e com os estudantes estagiários supervisionados pelos professores da universidade, pode-se promover um processo interativo de reflexão e de análise crítica em relação ao contexto sócio-histórico e às 
condições objetivas em que a educação escolar acontece." (p. 102). Portanto, reconhecemos o valor formativo dessa parceria entre a universidade e a escola na formação dos estagiários.

Quanto às orientações legais sobre o estágio, as Diretrizes Curriculares Nacionais para a Formação de Professores de Educação Básica (Resolução CNE/CP n ${ }^{\circ}$ 1/2002) e a Resolução CNE/CP $n^{0}$ 2/2002 sugerem que o mesmo deve ter no mínimo 400 horas, iniciar a partir da segunda metade do curso, ser desenvolvido em escola de Educação Básica e ser avaliado conjuntamente pela escola formadora e escola campo de estágio. Essas são as características básicas que o estágio deve possuir nos currículos dos cursos de formação de professores no Brasil.

A partir disso entendemos que nos cursos de formação de professores espera-se que o estagiário permaneça por um determinado período de tempo na escola e/ou em sala de aula sendo orientado pelo professor da Escola Básica e pelo professor da universidade a fim de aproximar-se do seu futuro campo de atuação, da profissão do professor e de suas práticas. É desejável que as relações entre orientadores e estagiários possuam um caráter pedagógico, de aconselhamento, de partilha de saberes, de complementação de práticas pedagógicas, de busca de solução para os problemas e de diálogo entre os profissionais reconhecidos e o aluno estagiário. Nesse sentido é que Pimenta e Lima (2004) ponderam que as atividades de orientação do estágio "requerem aproximação e distanciamento, partilha de saberes, capacidade de complementação, avaliação, aconselhamento, implementação de hipóteses de solução para os problemas que, coletivamente, são enfrentados pelos estagiários" (p. 114). A orientação do estágio não se configura, portanto, em uma atividade controladora ou de disputa de poder e autoridade. É, ao contrário disso, uma forma de auxiliar os estagiários a enfrentarem as pequenas dificuldades diárias de sala de aula, da vida na escola, do ser professor e a desenvolverem certa autonomia profissional para tais enfrentamentos.

Nesse artigo focamos nosso olhar somente para a orientação do estagiário por parte do professor universitário, e não por parte do professor da escola básica. Pensando nesse trabalho de orientação de estágio desenvolvido por esse profissional, em toda a organização e planejamento necessários pra tal, como Pimenta e Lima (2004) nos questionamos: "como alguém se torna professor de estágio? Como é ser professor orientador de estágio?" (p. 191).

O trabalho de orientação de estágio por parte do professor universitário envolve muitas atividades. Pimenta e Lima (2004), através de pesquisa desenvolvida com 
orientadores de estágio, apontam uma série de tarefas desenvolvidas pelos professores universitários que tem sob suas responsabilidades o estágio supervisionado como componente curricular dos cursos de formação de professores. Em meio a essas atividades as autoras citam a fundamentação teórica, a organização de materiais de ensino-aprendizagem, as observações das regências de classe dos estagiários, a troca de experiências com os estagiários, o diálogo a partir dos relatos e dos diários dos estagiários, a participação em eventos da escola, o retorno das atividades de estágio para as escolas através de reuniões. Percebemos então que a orientação e o acompanhamento dos estagiários requerem do professor universitário uma série de trabalhos específicos, por vezes distintos dos já desenvolvidos. A orientação do estágio é, portanto, um trabalho exigente ao professor universitário pois, dentre outros, requer um planejamento distinto, requer uma responsabilidade um tanto quanto maior por ultrapassar os limites da universidade atingindo Secretarias e/ou Coordenadorias de Educação e escolas.

Além das atividades referentes ao componente curricular do estágio, os orientadores muitas vezes são responsáveis por outros componentes curriculares e também desenvolvem diversas atividades que compõem o trabalho docente no ensino superior. Segundo Zabalza (2004) os professores universitários "desempenham, na realidade, um conjunto de funções que ultrapassa o exercício da docência” (p. 109). Esse conjunto de funções apontadas por Zabalza (2004) dizem respeito às atividades de pesquisa, de administração, de negociações, de relações institucionais, entre outras.

Muitas vezes o professor universitário possui uma ampla demanda de trabalho, marcada por normas e prazos. Os indicadores de qualidade da educação superior, a pontuação do currículo lattes, os pré-requisitos para o financiamento de uma pesquisa, os prazos de envio dos trabalhos a serem publicados, o calendário letivo, os relatórios, a participação em comissões e representações, a orientação dos alunos, entre outros, definem tempos, definem prioridades, exigem dedicação e acabam caracterizando cada professor no desenvolvimento do seu trabalho - trabalho que abrange também as atividades de orientação do estágio. Além das exigências da vida profissional, o professor também tem exigências da vida pessoal e, portanto, sua rotina pode se tornar uma inacabável lista de atividades a serem cumpridas. E todas essas demandas de trabalho acabam condicionando os modos de acompanhamento e orientação por parte do professor orientador junto aos seus alunos estagiários.

Reconhecemos que são muitas as funções assumidas pelo professor universitário orientador de estágio. O trabalho desse profissional é amplo, exige dedicação e tempo. 
Assim, muitas vezes, alguns professores universitários evitam assumir as disciplinas de estágio curricular porque sabem da demanda exigente desse trabalho. Há também aqueles professores universitários que menosprezam as disciplinas de estágio, pois as consideram menor ou de pouca importância comparada as demais disciplinas do curso que possuem, para eles, um caráter mais científico e teórico.

Segundo o Projeto Pedagógico do Curso de Licenciatura em Matemática (PP CLM, 2009) as "disciplinas que compõe o Estágio Obrigatório deverão ser ministradas por no mínimo dois professores, de forma compartilhada e cooperativa entre professores do Departamento de Matemática e Estatística e o Departamento de Ensino" (p. 46). De acordo com esse Projeto idealiza-se que dois professores universitários, em parceria, assumam o trabalho de formação, orientação e acompanhamento das disciplinas curriculares referentes ao estágio. Essa é uma proposta interessante pois valoriza o trabalho coletivo que pode estimular o diálogo, a troca de experiências, a partilha de conhecimentos e as aprendizagens conjuntas - o que certamente tende a aprimorar e qualificar a formação dos professores de matemática.

Para atingirmos nosso objetivo de conhecer e analisar o trabalho desenvolvido pelos professores universitários que orientam o estágio no Curso de Licenciatura em Matemática da UFPel utilizamos a entrevista como instrumento de coleta de dados. Entrevistamos dois professores orientadores, sendo um da área da matemática (denominado ficticiamente de Augusto) e a outra da área da educação (denominada ficticiamente de Fernanda). No momento da coleta dos dados, em 2009/II, esses professores orientadores estavam trabalhando com a disciplina denominada Estágio de Matemática II.

As análises apresentadas estão pautadas em Pimenta e Lima (2004) e Pimenta (2006) no que diz respeito ao estágio em curso de formação de professores, em Zabalza (2004) no que se refere ao professor universitário e em Zeichner (2009) no que se refere à formação dos formadores de professores. As orientações legais sobre o estágio curricular em cursos na formação de professores (Resoluções n. 1 e n. 2 de 2002 do CNE/CP e Resolução n. 3 de 2003 do CNE/CES) e o Projeto Pedagógico do curso pesquisado também nos deram bases para as análises desenvolvidas.

\section{A orientação do estágio em um curso de formação de professores: a visão dos orientadores}


O estágio curricular supervisionado do Curso de Licenciatura em Matemática pesquisado inicia no $5^{\circ}$ e termina no $8^{\circ}$ (último) semestre, sendo que sua carga horária de 442 horas é distribuída em quatro disciplinas: Trabalho de Campo I (85 h); Estágio de Matemática I (136 h); Trabalho de Campo II (85 h) e Estágio de Matemática II (136 h), localizadas, respectivamente, no $5^{\circ}, 6^{\circ}, 7^{\circ}$ e $8^{\circ}$ semestres (PP CLM, 2009). A primeira e a segunda disciplinas são implementadas em escolas de Ensino Fundamental (do $6^{\circ}$ ao $9^{\circ}$ ano) e as duas últimas em escolas de Ensino Médio (todos os anos) (PP CLM, 2009).

Essa caracterização do estágio nesse Curso nos mostra que o mesmo está de acordo com as orientações das Diretrizes Curriculares Nacionais para a Formação de Professores e com a Resolução do CNE/CP nº 2/2002: é desenvolvido em escola básica, possui carga horária maior do que as 400 horas sugeridas e começa no início da segunda metade do curso.

As disciplinas denominadas Trabalho de Campo objetivam "inserir o aluno nas escolas e nas salas de aula do Ensino Fundamental e Médio"; proporcionar ao aluno o conhecimento das "realidades escolares e os sistemas onde o ensino ocorre" e possibilitar ao aluno um "momento de olhar, ver e analisar as escolas existentes com olhos não mais de alunos, mas de futuros professores" (PP CLM, 2009). Já as disciplinas denominadas Estágio de Matemática destinam-se a regência de classe e aos processos de planejamentos das aulas e participação de reuniões tanto na universidade quanto na escola.

Como já mencionado, os orientadores que colaboraram com a pesquisa, no momento da coleta de dados, estavam responsáveis pela disciplina de estágio denominada Estágio de Matemática II. Esses orientadores foram os responsáveis pelo Trabalho de Campo II e Estágio de Matemática II, ou seja, não assumiram as quatro disciplinas referentes ao estágio nesse curso.

Entre as muitas atividades desenvolvidas por esses professores nos componentes curriculares denominados Trabalho de Campo II e Estágio de Matemática II elencamos que eles: preparavam os alunos para suas inserções em escolas de ensino médio públicas, davam suporte teórico aos estagiários, desenvolviam aulas de orientações gerais, trabalhavam conceitos específicos sobre a docência, orientavam os estagiários quanto a elaboração do plano de ensino, sugeriam leituras, ouviam relatos sobre as observações dos alunos nas escolas, faziam a leitura atenta dos projetos de ensino, davam o suporte burocrático necessário referente ao ingresso dos alunos nas escolas, 
orientavam os alunos quanto o desenvolvimento da regência de classe, faziam as visitas supervisionadas aos estagiários nas escolas, davam o feedback das visitas aos estagiários, tentavam estabelecer contato com o professor regente de classe, sanavam dúvidas dos alunos, apoiavam os alunos quanto as suas angústias, orientavam os alunos quanto a elaboração do relatório de estágio, incentivavam um olhar crítico quanto a atuação docente, avaliavam o relatório dos estagiários. O relato dos orientadores que apontou essas e outras atividades desenvolvidas pelos mesmos indica que o trabalho desenvolvido por esses profissionais é amplo e demanda dedicação de esforços e tempo.

No componente Trabalho de Campo II, apesar de predominar a atividade prática nas escolas, a professora Fernanda destaca que os alunos tiveram também aulas presenciais: No Trabalho de Campo II tivemos aulas na faculdade envolvendo leitura de textos, reflexões sobre o que é ser professor, o que é ensinar e aprender, trabalhos em grupo. [...] Também fizemos debates sobre as práticas pedagógicas observadas pelos estagiários nas escolas. Isso demonstra que esse componente curricular não é somente cumprimento de horas na escola, mas que existe um trabalho preparatório para os alunos irem a campo. Demonstra também que esses professores encararam o estágio como uma atividade teórica, instrumentalizadora para a práxis educacional e com possibilidades de transformação da realidade existente - conforme definido por Pimenta (2006).

A professora Fernanda relata ainda que no Trabalho de Campo II os estagiários tiveram que elaborar um projeto de ensino para ser desenvolvido no semestre subsequente, quando realizariam a regência de classe. Segundo a orientadora a intenção era de que a partir da observação o estagiário construísse seu projeto de estágio, um projeto inovador que poderia ser aplicado. O conhecimento da realidade escolar era valorizado para a elaboração do projeto de ensino e isso é positivo visto que a prática docente sempre deve ser uma prática contextualizada.

Um fato que desmobiliza com a lógica organizacional do estágio nesse Curso é a necessidade do estagiário ter que trocar de escola do Trabalho de Campo para a regência de classe, o que destacou a professora: alguns alunos observaram numa escola e não puderam estagiar nessa escola (Fernanda). É claro que isso ocorre por vários motivos, que podem ser provocados pela escola ou serem de responsabilidades dos alunos (incompatibilidade de horários, entre outros). A professora Fernanda expôs ainda que muitas escolas não estavam abertas para observações, somente para a regência de classe, ou seja, elas não queriam estagiários para conhecer a escola e observar os processos de 
ensino, de aprendizagem, de trabalho docente; mas sim, queriam estagiários principalmente para substituir o professor que estava em sala de aula. Todos esses desafios gerados pelo estágio deveriam ser bem geridos pela professora junto aos estagiários. Essas situações problemas requerem a implicação, um envolvimento maior do orientador junto ao estagiário que está em um momento importante da sua formação. Estando em um momento importante de sua formação o estagiário fica agitado e preocupa-se com situações de incerteza. E nesses momentos o orientador precisa transmitir segurança e confiança aos estagiários, precisa contemplar as angústias dos alunos e juntos encontrarem modos de enfrentamentos para os empecilhos.

Dentro de seu trabalho de orientação, os professores sugeriam que os estagiários desenvolvessem a regência de classe pelo período de um trimestre ou bimestre, dependendo do calendário da escola. O professor Augusto conta que a duração do estágio foi conforme o calendário da escola. Então, teve aluno que ficou praticamente um trimestre inteiro [...] e outros que tiveram apenas de 30 a 50 horas de estágio em sala de aula. A permanência na regência de classe por um bimestre ou trimestre possibilita que o estagiário vivencie uma sequência de ações docentes que o tornam "responsável por tarefas em ordem crescente de complexidade" (Resolução do CNE/CES n ${ }^{0} 3 / 2003$ ) - mas, como indicou o professor, nem sempre isso é possível, devido a várias condicionantes - algumas dessas serão apontadas no decorrer do texto.

No início da disciplina de Estágio de Matemática II, segundo os professores, foi proposto um encontro com todos os alunos da turma para orientações gerais quanto ao desenvolvimento da regência de classe e esclarecimentos sobre essa prática. Posteriormente a esse momento, as orientações ocorriam a partir da procura dos alunos, através de seções individuais de orientação. Segundo o professor Augusto: nós [aluno e professor] agendávamos um horário de orientação individual, o aluno ia até a minha sala e nós conversávamos cerca de uma hora à uma hora e meia. [...] Eles expressavam as dificuldades que estavam tendo em sala. Esses encontros se caracterizavam pela escuta, pelo diálogo ou pelo aconselhamento e busca de solução para os problemas enfrentados pelos estagiários - como sugerido por Pimenta e Lima (2004). Como as orientações individuais ocorriam a partir da busca dos próprios estagiários, a frequência das mesmas variou de aluno para aluno, como expresso pelo orientador: A orientação ocorria a partir da procura deles, de suas necessidades. [...] Alguns alunos tiveram um encontro para orientação, mas a grande maioria teve dois ou três (Augusto). 
Entendemos que a avaliação que o orientador faz do estagiário deve se caracterizar pelo acompanhamento do processo de desenvolvimento do professor em formação, podendo o orientador fornecer informações desse processo aos estagiários a fim de oportunizar o aperfeiçoamento da prática pedagógica dos alunos. Assim sendo, a atuação do professor orientador é importante no processo formativo dos professores em formação na medida em que pode colaborar significativamente para que o aluno pense, estude, reflita e tenha condições de aprimorar-se como professor.

No curso pesquisado os professores orientadores relatam que utilizaram como instrumento de avaliação do estágio o plano de ensino (na disciplina de Trabalho de Campo II) e as visitas supervisionadas e o relatório de estágio (na disciplina de Estágio de Matemática II), o que é expresso no seguinte depoimento: No Trabalho de Campo II eles propuseram um projeto de estágio baseado nas observações que fizeram. A avaliação do Estágio é feita através de um relatório. [...] Então, a avaliação é feita em cima desses dois pontos: o projeto de estágio e o relatório de estágio. A visita ao estagiário também faz parte da avaliação (Augusto). Percebemos que, como apontam Pimenta e Lima (2004), o instrumento de avaliação utilizado com mais frequência pelos professores orientadores de estágio é o relatório. Os professores não mencionaram terem feito nenhum outro tipo de atividade que previsse um retorno das atividades desenvolvidas as escolas campo de estágio - o que pode caracterizar certo distanciamento entre essas duas instituições de ensino.

Todo o processo de avaliação do estágio desse Curso é feito pelos professores orientadores de estágio, sem a participação dos professores da escola básica. A professora Fernanda descreve esse processo da seguinte maneira: Eu e o professor da matemática dividimos a turma, eu fiz observação de alguns e ele de outros alunos. [...] Também dividimos os relatórios dos estagiários para ler e depois nos reunimos para elaborar o resultado final. Os professores orientadores dividem o trabalho por número de alunos, ou seja, avaliam os projetos e planejamentos e fazem as visitas supervisionadas de determinados alunos. A mesma professora ainda destaca: Um problema do estágio é essa separação: um professor da faculdade de educação trabalhando a parte da educação e o da matemática trabalhando o conteúdo específico, sem estarem articulados. É fundamental eles estarem articulados. [...] O ideal seria que o professor do conhecimento específico e o formado em pedagogia pudessem fazer as observações do estagiário juntos. A própria orientadora reconhece que o trabalho de orientação de estágio ficaria mais bem qualificado se esses dois profissionais tivessem 
condições de planejar e desenvolver o trabalho juntos, se eles realmente tivessem condições de ministrar as disciplinas referentes ao estágio conjuntamente. Esse problema apontado pela professora mostra que talvez o Curso pode não estar integrando os conhecimentos matemáticos e pedagógicos ou que o trabalho cooperativo entre os dois professores, proposto pelo Projeto Pedagógico, não está se efetivando. Talvez fosse necessário se pensar em estratégias e condições de trabalho docente para que realmente fosse possível a proposta do Projeto Pedagógico: um trabalho de forma compartilhada e cooperativa entre os professores.

Os professores da escola básica não participaram da avaliação dos estagiários, conforme apontado pelo orientador: Nesse semestre optamos pelo professor da escola não participar da avaliação do estagiário, até pela indicação da $C R E^{3}$ de que eles não fariam isso ou seriam poucos que fariam. [...] Nós tentamos conversar com a maioria dos professores, mas não tivemos acesso a todos (Augusto). Percebemos dois aspectos nesse relato: 1. os professores da escola (ou a CRE) não se sentem parte do processo e, 2. os professores da universidade assumem sozinhos a responsabilidade da avaliação. A não participação da escola na avaliação do estágio não está de acordo com a orientação das Diretrizes Curriculares Nacionais para a Formação de Professores: o estágio curricular supervisionado deve ser avaliado conjuntamente pela escola formadora e a escola campo de estágio (BRASIL, 2002, Artigo $13^{\circ}, \S 3^{\circ}$ ). Assim, sugerimos: 1 . que a Universidade reconheça o professor da escola como um orientador que pode/deve participar da avaliação do estágio; 2. que o próprio professor da escola tome consciência de que é um orientador do estagiário, é um profissional competente escolhido como guia e modelo pelo estagiário e, assim, deve participar da avaliação do mesmo. Acreditamos, como apontam os próprios estagiários de um estudo desenvolvido por Pimenta e Lima (2004, p. 107), que "uma parceria mais viva e eficaz entre a universidade e a escola" tenderia a proporcionar mais conhecimentos e aprendizagens para ambas as partes.

Os professores orientadores contaram que na maioria dos casos só conseguiram fazer uma visita a cada estagiário, como relatado: Tentamos observá-los em três momentos distintos, mas não foi possível em todos os casos. Na maioria dos casos observamos só uma vez (Augusto). Pimenta e Lima (2004, p, 2009) nos seus estudos também indicam "a dificuldade de visita do orientador ao local de estágio". A

${ }^{3}$ Coordenadoria Regional de Educação. 
quantidade de visitas possíveis aos estagiários está estritamente ligada à carga horária e quantidade de turmas e alunos destinados aos profissionais de ensino. Se esse orientador tivesse sob sua responsabilidade dez alunos estagiários, sua intenção inicial seria fazer trinta visitas (um número significativo), porém as condições reais de trabalho desse professor fizeram com que o mesmo conseguisse desenvolver somente um terço de sua meta idealizada. Possivelmente os professores orientadores de estágio desse Curso tinham uma disponibilidade de horários limitada para a realização das visitas. Além disso, é necessário considerar que não existe um sistema de ajuda ou auxílio para que esses professores possam se locomover até as escolas. Não existe um carro ou transporte específico tampouco existe ajuda de custo para essas despesas geradas por esses deslocamentos. Percebemos aqui a grande demanda de trabalho do professor orientador de estágio e a falta de condições de trabalho para que o mesmo consiga atingir os objetivos idealizados e desejados.

Quanto as visitas supervisionadas às aulas desenvolvidas pelos estagiários e o feedback por parte do orientador, o professor Augusto relata o seguinte: em encontro individual eu passo pros alunos o que observei nas aulas que assisti. Sugiro algumas mudanças em termos de posicionamento, de conteúdo. [...] mais em termos de experiências, de vivência em sala de aula, de como lidar com o aluno. Após a observação o orientador encontra o estagiário na universidade e os dois conversam sobre as práticas desenvolvidas pelo professor em formação. Parece-nos que esse encontro valoriza o diálogo, a troca de experiências. O feedback também é importante para a formação dos estagiários na medida em que, como destaca Zabalza (2004), marca a auto-imagem dos alunos. Já a professora Fernanda mencionou que não tinha muito contato com os estagiários quando estes estavam desenvolvendo o Estágio II: $O S$ estagiários tinham mais contato com o professor orientador de estágio da matemática porque eles se encontravam em outras disciplinas e assim aproveitavam e tiravam dúvidas. Cabe aqui um reposicionamento da professora quanto ao acompanhamento dos estagiários; o fato de ela não ser responsáveis por outras disciplinas do curso e de não pertencer ao mesmo centro de ensino não a desresponsabiliza de acompanhar, de estar próxima, de visitar e de conversar com os alunos estagiários.

A professora Fernanda apontou que uma limitação quanto ao desenvolvimento do estágio é a divergência entre os calendários da Universidade e das escolas. Esse fato é comum a diversos estagiários de distintas universidades e cursos de formação de professores. Pimenta e Lima (2004, p. 104) também assinalam esse fato ao apontarem 
que uma das dificuldades "com que se defrontam os alunos que se iniciam nas atividades de formação de professores é o descompasso entre hábitos, calendários e demais atividades e rotinas da universidade e da escola". A gripe $\mathrm{A}^{4}$ (do inverno de 2009), o atraso (devido a greve) no início do semestre da UFPel, entre outros, segundo o professor Augusto, também interferiram para que houvessem impasses para a regência de classe dos alunos e para as visitas supervisionadas por parte dos professores orientadores.

Outro aspecto que merece destaque é o fato de a professora Fernanda, da área da educação, ser uma professora temporária, ou seja, não efetiva da UFPel. Essa professora conta que quando contratada assumiu 20 horas semanais de atividades, porém, com o tempo, teve que assumir 40 horas. Conta também que o desenvolvimento do seu trabalho não foi como o desejado, pois tinha outros trabalhos fora da Universidade. Outros estudos sobre estágio também chamam a atenção e questionam o fato de professores substitutos serem responsabilizados pelas disciplinas de estágio pois os mesmos, muitas vezes, são inexperientes e estão em uma condição provisória, condições que podem influenciar na organização do trabalho desses professores. Frente a essas evidências, concordamos com Zeichner quando aponta que

É necessário mais pesquisas que investiguem as consequências de quem [...] está supervisionando um aluno que participa de um estágio em uma determinada escola. Qual é a importância se os formadores e os supervisores de estágio em cursos de formação inicial são do corpo permanente e da equipe acadêmica ou do corpo de profissionais contratados ou doutorandos? $(2009$, p. 1)

Entendemos que o papel do orientador é de fundamental importância para a formação dos estagiários, futuros professores. As condições de trabalho, a formação, o regime de trabalho, o caráter do contrato do professor orientador, entre outros, são fatores que também influenciam implicitamente no trabalho de acompanhamento e orientação do estágio desenvolvido pelos mesmos nos cursos de formação de professores.

\section{Apontamentos finais}

\footnotetext{
${ }^{4}$ Essa doença respiratória aguda afetou muitas pessoas no inverno de 2009 no Brasil, especialmente no Sul. A gripe A é causada pelo vírus influenza A H1N1 e ficou conhecida popularmente como gripe suína. Devido a isso muitos estabelecimentos, como escolas e universidades, tiveram que suspender suas atividades por um determinado período. E isso acabou influenciando no desenvolvimento dos estágios para o contexto pesquisado.
} 
A tentativa de conhecer e analisar o trabalho desenvolvido pelos professores universitários que orientam o estágio no Curso de Licenciatura em Matemática da UFPel nos mostrou que a demanda desse trabalho é ampla e carece de condições mínimas para ser bem desenvolvido. Através do relato dos orientadores tivemos condições de identificar algumas limitações referentes à orientação do estágio que fogem do controle dos professores, como, por exemplo, o descompasso entre o calendário escolar e o calendário universitário ou a incompatibilidade de horários entre o orientador e o estagiário.

Reconhecemos a grande influência que o orientador exerce na formação dos futuros professores e a importância do seu papel de aconselhar, partilhar saberes e experiências junto aos estagiários que estão se inserindo nas escolas e vivenciando experiências marcantes para a construção de suas identidades docentes. Portanto, deveríamos pensar em estratégias que visassem à melhoria das condições de trabalho dos orientadores de estágio para, assim, desenvolver um trabalho com mais qualidade, para estar mais próximos dos estagiários e para ter novas perspectivas de aproximações entre universidade e escola básica.

Como Zeichner (2009) apontamos a necessidade de se realizarem mais pesquisas sobre os formadores de professores, sobre as características desses formadores e sobre como esses formadores estão formando os novos professores. Assim poderíamos pensar e sugerir melhores condições para o desenvolvimento do trabalho de orientação de estágio bem como propor melhorias frente às possíveis necessidades formativas do orientador.

\section{REFERÊNCIAS}

BRASIL. CNE. CP. Resolução $n^{0}$ 1, de 18 de fevereiro de 2002: Institui Diretrizes Curriculares Nacionais para a Formação de Professores da Educação Básica, em nível superior, curso de licenciatura, de graduação plena. Disponível em: 〈http://portal.mec.gov.br/cne/arquivos/pdf/rcp01_02.pdf>. Acesso em: 13 jun. 2013.

BRASIL. CNE. CP. Resolução ${ }^{\circ}{ }^{2}$, de 19 de fevereiro de 2002: Institui a duração e a carga horária dos cursos de licenciatura, de graduação plena, de formação de professores da Educação Básica em nível superior. Disponível em: 〈http://portal.mec.gov.br/cne/arquivos/pdf/CP022002.pdf>. Acesso em: 13 jun. 2013.

BRASIL. Conselho Nacional de Educação. Câmara de Educação Superior. Resolução CNE/CES n ${ }^{\circ}$ 3, de 18 de fevereiro de 2003: Estabelece as Diretrizes Curriculares 
para os cursos de Matemática. Disponível em:

〈http://portal.mec.gov.br/cne/arquivos/pdf/ces032003.pdf>. Acesso em: 13 jun. 2013.

PIMENTA, Selma Garrido. O estágio na formação de professores: unidade teoria e prática? $7^{\mathrm{a}}$ ed. São Paulo: Cortez, 2006.

PIMENTA, Selma Garrido; LIMA, Maria Socorro Lucena. Estágio e docência. 2. ed. São Paulo: Cortez, 2004.

UFPEL. IFM. Projeto Pedagógico Licenciatura em Matemática. Pelotas, UFPel: 2009.

ZABALZA, Miguel Ángel. O ensino universitário: seu cenário e seus protagonistas. Porto Alegre: Artmed, 2004.

ZEICHNER, Kenneth M. Uma agenda de pesquisa para a formação docente. In:

Revista Brasileira de Pesquisa sobre Formação de Professores. Volume 01 / n. 01 ago.-dez. 2009. Disponível em:

〈http://formacaodocente.autenticaeditora.com.br/artigo/exibir/1/8/1 >. Acesso em: 03 jul. 2013.

\section{Como referenciar este artigo}

FELDKERCHER, Nadiane. O trabalho dos professores orientadores de estágio em cursos de formação de professores. Revista Ibero-Americana de Estudos em Educação, Araraquara, v. 11, n. 4, p. 1799-1813, 2016. Disponível em: <http://dx.doi.org/10.21723/riaee.v11.n4.6032>. E-ISSN: 1982-5587.

Submetido em: agosto/2013

Aprovação final em: abril/2016 